EIXO TEMÁTICO: Formação docente e currículo

\title{
FORMAÇÃO DE PROFESSORES: REFLETINDO SOBRE UMA EXPERIÊNCIA EM UM CURSO DE $2^{\text {a }}$ LICENCIATURA \\ FORMACIÓN DE PROFESORES: REFLEXIÓN DE UNA EXPERIENCIA EN UN CURSO DE $2^{\text {a }}$ LICENCIATURA
}

\author{
SILVA, A. C. R ${ }^{1}$, CARVALHO, M. de L. D. de ${ }^{2}$ \\ ${ }^{1}$ Instituto Federal de Educação, Ciência e Tecnologia do Rio Grande do Norte -IFRN \\ ${ }^{2}$ Universidade do Minho - UM \\ E-mail para contato: amelia.reis@ifrn.edu.br \\ lurdesdc@.ie.uminho.pt
}

\begin{abstract}
RESUMO - Apresentaremos parte de uma pesquisa doutoral, ainda em andamento. Trata-se de uma investigação sobre a implantação de um curso de segunda licenciatura em Ciências da Natureza e Matemática, ofertada pelo Instituto Federal de Educação, Ciência e Tecnologia do Rio Grande do Norte -IFRN, através do Plano Nacional de Formação de Professores da Rede Básica - PARFOR. Objetiva identificar e analisar no contexto do PARFOR quais as contribuições do Curso de $2^{a}$ Licenciatura ofertada pelo IFRN para a qualidade da formação/profissionalização dos docentes cursistas, tendo dentre os seus objetivos traçar um diagnóstico do percurso formativo dos formandos e as suas necessidades de formação. Adotando como metodologia um estudo de caso participativo, desenvolvida no IFRN, campus Pau dos Ferros, em uma turma de $2^{a}$. Licenciatura em Ciências da Natureza e Matemática envolvendo os gestores $(n=1)$, formadores $(n=14)$ e formandos $(n=12)$ do Curso. Os resultados apontam que as instituições que se propõem a ofertar cursos através do PARFOR que tem em sua gênese uma proposta de formação diferenciada, devem levar em consideração na elaboração de seus projetos, as as histórias de vida pessoal e profissional dos participantes. Não deve ser desconsiderado que esses docentes-estudantes trazem consigo uma gama de experiências e que se pretende que sistematizem, integrem e mobilizem os novos conhecimentos, de forma que possam contribuir verdadeiramente para a mudança da sua efetiva prática. Essa mudança deve ser provocada através de práticas reflexiva que apontem para a necessidade de agir em diferentes situações e enfrentar possíveis mudanças na sua atuação.
\end{abstract}

PALAVRAS-CHAVE: Formação Docente, Prática reflexiva, Formação continuada

RESUMEN - Presentamos una parte de una pesquisa doctoral, aun en desarrollo. Se trata de una investigación acerca de la implementación de un curso de Segundo Grado en Ciências de la Naturaleza y Matemáticas, ofertada por el Instituto Federal de Educación, Ciencia y Tecnología de Rio Grande del Norte - IFRN, a través del Plano Nacional de Formación de Profesores de la a Rede Básica-PARFOR. Objetiva identificar y analizar en el contexto del PARFOR cuáles son las contribuciones del Curso de $2^{a}$ Licenciatura ofertada por el IFRN para la calidad en la formación/profesionalización de los profesores- 
estudiantes, teniendo como sus objetivos trazar un diagnóstico del trayecto formativo de los estudiantes y sus necesidades de formación. Adoptando como metodología un estudio de caso participativo, desarrollada en el IFRN, campus Pau dos Ferros, en un grupo de $2^{a}$. Licenciatura en Ciências de la Naturaleza y Matemáticas envolviendo los gestores $(n=1)$, formadores $(n=14)$ y estudiantes $(n=12)$ del Grado. Los resultados apuntan que las instituciones que se propone a ofertar cursos a través del PARFOR que tiene en su génesis una propuesta de formación diferenciada, deben llevar en consideración en la elaboración de sus proyectos, las historias de vida personal y profesional de los participantes. No debe ser desconsiderado que eses docentes-estudiantes traen consigo una gama de experiencias y que se pretende que sistematicen, integren y movilicen los nuevos conocimientos, de forma que puedan contribuir verdaderamente para el cambio de su efectiva práctica. Ese cambio debe ser provocado a través de prácticas reflexivas que apunten para la necesidad de actuar en diferentes situaciones y enfrentar posibles cambios en su actuación.

PALABRAS CLAVE: Formación Docente, Práctica reflexiva, Formación continuad

\section{INTRODUÇÃO}

Em se tratando de assuntos educacionais, vários são os questionamentos que tem despertado o interesse dos pesquisadores que atuam na área de Educação e Formação de Professores. A pesquisa aqui apresentada é parte integrante de um projeto de doutorado em que se pretende evidenciar a relevância da formação continuada de professor, que tem como problemática de investigação identificar e analisar as contribuições do Curso de Segunda Licenciatura para a qualidade da formação/profissionalização dos docentes no contexto do Plano Nacional de Formação de Professores da Educação Básica - PARFOR, ofertada pelo Instituto Federal de Educação, Ciência e Tecnologia do Rio Grande do Norte - IFRN. Optamos por realizar um estudo de caso (YIN, 2005) participativo a partir da avaliação do desenvolvimento do projeto de Curso ofertado pelo IFRN, tendo como sujeitos participantes os formadores, formandos e coordenação de curso.

Seguindo as premissas da Política Nacional de Formação de Professores desenvolvida no Brasil, o IFRN aderiu à oferta através do Programa do Plano Nacional de Formação de Professores da Educação Básica, optando por iniciar com oferta de Curso de Segunda Licenciatura ${ }^{1}$.

Envolta desde no início e desenvolvimento deste curso, alguns temas começaram a nos inquietar. Foi então que entendemos que o acompanhamento mais profícuo poderia contribuir

\footnotetext{
${ }^{1}$ Os cursos de Segunda Licenciatura é uma das possibilidades de ofertas através do PARFOR e são direcionados para docentes em exercício na rede pública da educação básica, há pelo menos três anos, em área distinta da sua formação inicial (ex: professor com formação em Pedagogia ministrando aula de Matemática).
} 
para uma reflexão mais aprofundada sobre a necessidade de formação dos docentes, como se sentiam enquanto profissionais e em que perspectiva o curso que estava sendo ofertado atenderia aos anseios dos mesmos.

Diferentes questões começaram a inquietar-nos, dentre elas, saber o que leva um professor que já tem uma formação superior inicial, que atua na docência, a procurar fazer um novo curso de Licenciatura. Toda essa inquietação foi aflorada ao constatarmos que os docentes que participavam do curso não tinham nenhum tipo de liberação dos seus afazeres laborais ou diminuição da carga-horária a ser cumprida nas escolas em que lecionavam. Para além disso, outro fator significativo seria a ausência de qualquer incentivo financeiro ao término do curso.

Se entendemos a formação docente como um processo contínuo, especialmente em se tratando de professores que já possuíam uma formação inicial, experiências de vida e profissional acumuladas, precisaríamos ouvir e dar voz a todos os envolvidos no processo da investigação. Trata-se, portanto, de perceber a qualidade do curso ofertado, se realmente atende aos anseios dos docentes-estudantes, possibilitando que os mesmos adquiram e/ou aperfeiçoem seus conhecimentos teóricos e práticos, concernentes à docência e, em que perspectiva essa investigação, pode, junto aos envolvidos, contribuir para ajustes e melhorias futuras. Corroborando com essa linha de pensamento, Morgado (2005, p. 114-115) alude a Fernando Gonçalves (2003) e diz que:

A formação contínua "deverá estar dirigida para um professor que se assume
como um ser em autotransformação". Considera, ainda, que para a formação
contínua poder constituir um recurso valioso para os docentes, é necessário
que estes "se sintam responsáveis construtores" da comunidade escolar e se
encontrem envolvidos num contexto que, por ser dinâmica, exige, cada vez
mais, actos de personalização da gestão da prática educativa. A formação
contínua será, assim, uma formação "solicitada e constituída a partir das
dificuldades e carências que o professor enfrenta diariamente", isto é, "uma
formação solicitada, mas emergente de forma contextualizada".

\subsection{OS CAMINHOS METODOLÓGICOS}

Após delimitarmos a problemática, definirmos as questões de investigação e os participantes da pesquisa, definimos as técnicas e os instrumentos de recolha de dados que seria realizado com cada um dos grupos participantes. Esta definição se apresenta como de suma importância, pois através das informações apresentadas pelos dados é que podemos 
refletirmos e respondermos sobre as nossas questões de investigação.

Fizemos uso de diversos técnicas de recolha durante os quatro semestres de desenvolvimento do curso com início no segundo semestre do ano de 2012 indo até o primeiro semestre do ano letivo de 2014. Utilizamos portfólios dos formandos, questionários aplicados a formadores e formandos, entrevista com a coordenadora, além de uma análise documental com enfoque no Projeto Pedagógico do Curso. O conjunto de todas essas técnicas, nos permitiu fazer um acompanhamento do desenvolvimento e processos curriculares e de aprendizagem durante os quatro semestres que compõem o curso. Salientamos que, no presente texto, utilizamos apenas os dados obtidos a partir da leitura dos portfólios elaborados pelos docentes-estudante durante o primeiro semestre.

\subsection{CONHECENDO OS FORMANDOS}

Para traçarmos a representação do grupo aplicamos um questionário junto aos formandos, que apontamos como indicadores informações referentes ao sexo, idade, formação acadêmica em primeira licenciatura, ano de conclusão, tempo de experiência como professor, disciplina e séries que atuam, frequência a curso de pós-graduação, além de questionarmos qual deles possuía experiência profissional diferente da docência.

Dos respondentes, em um total de doze, em relação ao sexo, $40 \%$ dos formandos eram do sexo feminino e $60 \%$ do sexo masculino. Muito embora a amostra seja reduzida, não deixa de se assinalar que estes dados vão no sentido oposto a vários estudos (INEPE-MEC, 1997) que apontam a profissão docente como uma profissão feminina.

Quanto a faixa etária, variavam entre trinta e quatro e cinquenta e dois anos de idade. Verifica-se uma grande amplitude e heterogeneidade entre os inquiridos, além do fato de percebermos que todos já possuíam vários anos de docência, sendo que: nenhum inferior a cinco anos, dois mais de vinte anos de atuação profissional, mas todos continuavam buscando uma formação continuada.

No que concerne a formação inicial, Gatti (2009) nos aponta que a maioria dos professores que lecionam até o $9^{\circ}$ ano, possuem formação em Pedagogia sendo crescente a oferta de vagas para a formação de professores polivalentes, conforme veremos no quadro a 
seguir sobre as ofertas de graduação presenciais no Brasil. Para fins de esclarecimento, a autora denomina de Licenciatura I os cursos destinados à formação infantil e séries iniciais do Ensino Fundamental e Licenciatura II os direcionados à formação de professores das disciplinas específicas.

\begin{tabular}{|l|c|c|c|}
\hline \multirow{4}{*}{ Licenciatura I } & Período & Cursos & Matrículas \\
\hline \multirow{4}{*}{ Licenciatura II } & 2001 & 1.224 & 259.575 \\
\cline { 2 - 4 } & 2006 & 2.415 & 356.168 \\
\cline { 2 - 4 } & \% Cresc. & $(97,30)$ & $(37,21)$ \\
\hline \multirow{4}{*}{ Total } & 2001 & 3.307 & 575.809 \\
\cline { 2 - 4 } & 2006 & 5.041 & 805.947 \\
\cline { 2 - 4 } & \% Cresc. & $(52,40)$ & $(40,00)$ \\
\hline & 2001 & 4.531 & 835.384 \\
\cline { 2 - 4 } & 2006 & 7.456 & 1.162 .115 \\
\cline { 2 - 4 } & \% Cresc. & $(64,60)$ & $(39,10)$ \\
\hline
\end{tabular}

Quadro 1- Sinopse Estatística da Educação Superior 2001 e 2006

Fonte: Gatti (2009, p. 57).

Com o grupo inquerido, a situação não é diferente, pois $70 \%$ deles possuí formação em Pedagogia e atuam em diferentes disciplinas, com concentração para as Disciplinas de Matemática e Ciências, o que deve ter impulsionado para escolha do curso. Percebemos que em sua integralidade, nenhum tinha menos de cinco anos de conclusão da $1^{\text {a }}$. Licenciatura, e que apenas quatro ainda não tinha feito nenhuma pós-graduação, sendo que apenas dois deles tinha tido experiência profissional em área distinta à educacional.

\section{O QUE PENSAM OS PROFESSORES ESTUDANTES: UMA ANÁLISE A PARTIR DOS PORTFÓLIOS}

A palavra portfólio tem uma etimologia ligada às artes visuais. Sua origem, do italiano "portafoglio", remonta ao século XVIII, quando era usada para designar uma valise feita para carregar folhas soltas de papel. O termo deriva do verbo latino "portare" (transportar) e do substantivo "foglio" (folha) e designa a pasta que contém desenhos, fotos, textos, pautas de música, seja de profissionais diversos ou de alunos. 
No âmbito educacional, o portfólio é muito mais do que esse conjunto de folhas, mas envidados esforços para uma compreensão adequada dos seus aspectos positivos, passa a ser uma estratégia de formação, investigação e avaliação que, por sua natureza, pode contribuir para melhoria na qualidade da formação, pois estimula aos que o elaboram uma reflexão e conscientização sobre aquilo que narram. Diferente de outros instrumentos, o portfólio distingue-se de outros, como por exemplo o caderno de anotações referentes aos conteúdos de aulas. Nesse caso, o papel é apenas de organizar o material, já no caso dos portfólios, todas as fases do processo têm um sentido próprio, mesmo em construção são processos de investigação dos estudantes, onde expressam seus sentimentos, impressões e opiniões sobre o que está sendo trabalhado e a metodologia adotada. Ou seja, "proporciona evidências do conhecimento que foi construído, das estratégias utilizadas e da disposição de quem o elabora em continuar aprendendo" (HERNÁNDEZ, 1998, p. 10).

Assim sendo, como refere Fernandes (citado por VEIGA SIMÃO, 2005, p. 281) os portfolios podem

Dar origem a uma outra "cultura", a uma outra ideia de sala de aula, tornando-o num local onde as aprendizagens se vão construindo em conjunto e individualmente ao ritmo de cada um; em que se reflecte e pensa em que se valorizam as experiências, instituições e saberes de cada aluno, em que se acredita que as dificuldades podem ser superadas e em que, essencialmente, se aprende.

Nesse sentido, o que se esperava na proposta avaliativa ao final do primeiro semestre do curso de Ciências da Natureza e Matemática através desse instrumento é que não fossem feitas apenas reproduções de conteúdos vivenciados em cada uma da disciplina. Mas, que os educandos pudessem, já ao final do primeiro semestre, se desnudarem através da escrita, se colocando enquanto um profissional que já atuante em sua vida docente, pudessem refletir sobre as suas experiências docentes, os conhecimentos conceituais e metodológicos, as suas motivações, enriquecendo o processo metodológico de avaliação.

Sendo o portfólio considerado como um instrumento de avaliação investigativa, implementado de forma inicial, serve para o professor formador adquirir informações necessárias para gerar novos conhecimentos, assim como para os estudantes perceber o que já sabe e o que ainda pode avançar na aprendizagem de conteúdos e procedimentos. A reflexão a 
partir da leitura desses documentos é importante para os docentes, pois segundo Perrenoud (2002, p. 51)

Nem toda experiência gera automaticamente aprendizagens. Uma rotina eficaz tem justamente como virtude dispensar todo o questionamento. O ser humano aspira ao encontro dessas rotinas, à ação sem desespero. Nesse caso, sua experiência só é fonte de auto-informação no sentido restrito de reforço daquilo que está funcionando bem.

Mesmo quando sua experiência ainda não é um longo rio sereno ou quando surgem corredeiras inesperadas, a reflexão provocada por elas não desemboca necessariamente em saberes capazes de serem reaproveitados em outras situações. Uma parte da reflexão sobre a ação produz um ajuste pragmático. $\mathrm{O}$ professor aprende, por exemplo, a dar orientações mais precisas para evitar mal-entendidos, para controlar as conversas paralelas à aula, para prevenir a agitação, para formular as provas de uma maneira que facilite as correções, para não iniciar uma atividade quando não há tempo suficiente para termina-la antes do fim do período letivo, etc. Essas aprendizagens se traduzem em novas condutas, as quais sem dúvida, são acompanhadas, ao menos na sua origem, de um raciocínio quase explícito. No entanto, depois que o problema tiver sido resolvido, o o professor pode ligar de novo o piloto.

No processo formativo, o portfólio constitui-se como um instrumento facilitador para estabelecer uma conexão entre a teoria e a prática, um instrumento de reflexão passivo de ser aplicado nos campos pessoal e profissional. Podemos pensar como uma forma de narrativa que é escrita para produção do conhecimento para o próprio sujeito, em um ir e vir de suas leituras e releituras, que o levem a auto reflexão do seu saber, saber-fazer, saber-ser e estar.

Como mencionado anteriormente, traçar um diagnóstico do percurso formativo dos formandos e as suas necessidades de formação, esse foi um dos objetivos delineado que esperamos encontrar respostas a partir da leitura e análise dos portfólios. Para tanto, elegemos cinco categorias de análise que foram definidas a priori, sendo elas: Experiências anteriores, Motivação inicial e expectativas sobre o curso, Aquisição de conteúdos, Reflexão sobre a prática e Contribuição para a formação continuada. Posteriormente, duas subcategorias - a aquisição de conteúdos conceituais e aquisição dos conceitos metodológicos - surgiram após a primeira leitura flutuante dos textos. Ressaltamos nossa compreensão que é apenas uma forma organizacional, muito embora entendamos que no desenvolvimento da prática de ensino não há necessariamente, uma linearidade nas ações. 
No que tange as Experiências Anteriores não tínhamos o objetivo de reconstruir a história de vida dos professores, mas observamos relatos de experiências que antecediam ao curso, considerando que todos os formandos já eram docentes. Todos os Docentes-estudantes já haviam atingido a fase que Tardif (2002) denomina de "fase da estabilização e de consolidação", pois todos possuíam mais de três anos de docência, tendo alguns deles já ultrapassado essa fase por possuir mais de sete anos de docência.

Ao longo dos portfólios, observamos que os formandos ainda se colocaram muito timidamente para falarem de suas práticas e experiências. Questionamos então: seria insegurança pelo trabalho desenvolvido? Faltaria a construção dessa autoconfiança? Os inquiridos consideram que uma prática docente não constitui necessidade de um registro do que desenvolve em sua sala de aula? O que percebemos é que a maioria se deteve a descrever a falar sobre sua formação acadêmica anterior. Vejamos algumas demonstrações: "Sou professor polivalente desde 1993 com formação em Pedagogia e especialização em História" (PORTFÓLIO 1, 2012).

Eu, graduada em Letras pela Universidade Estadual do Rio Grande do Norte (UERN), Pós-graduada em Psicopedagogia pela Fundação Integrada de Patos (FIP), Professora das Disciplinas de Língua Portuguesa e Língua Inglesa na rede Pública Estadual do Rio Grande do Norte. (PORTFÓLIO 2, 2012).

Um ponto que nos instigou fortemente foi entender qual a motivação inicial que levaram a procura do curso de Segunda Licenciatura em Ciências da Natureza e Matemática ofertado pelo IFRN e quais expectativas aqueles docentes-estudantes tinham sobre o curso que passaria a frequentar. A escolha pela área já ficava evidenciada pela exigência que o PARFOR apresentava que era de estar ministrando disciplinas diferente da sua formação. Mas, se esses professores já possuíam uma formação de Nível Superior, não teriam direito a redução de sua carga-horária e nem aumento salarial o que o motivava a procurar por essa formação continuada, tornou-se um ponto a ser buscado.

Os registros dos formandos ao se referirem às suas motivações demonstram entusiasmo, embora, não evidenciem tão claramente em que sentido o curso poderia contribuir em termos pessoal e/ou profissional. A docência é uma profissão repleta de desafios, o que faz com que estes profissionais busquem novas formações, na procura por respostas aos problemas cotidianos postos pela prática diária. 
O que verificamos é a felicidade de voltar a vida acadêmica, ressaltando em alguns relatos e a importância do aprofundamento dos conhecimentos das disciplinas que lecionavam: "É possível afirmar, portanto, que a segunda licenciatura em Ciências da Natureza e Matemática foi um presente, espero que ele esteja recheado de conhecimentos e experiências que possam contribuir não só para o meu trabalho, mas também para a minha vida”. (PORTFÓLIO 3, 2012).

Popularmente, sempre ouvimos dizer que para atuar como docente, basta saber dos conteúdos a serem ensinados. No entanto, sabemos que isso não é suficiente, sendo necessário a formação específica para tal e, para além da formação inicial pensarmos o lugar onde se ensina, a quem e como se ensina. Assim, foi que percebemos o destaque nos escritos dos formandos sobre a Aquisição de conteúdos, ressaltando a aquisição não apenas dos conteúdos conceituais, mas colocando também os conteúdos metodológico em uma posição de destaque.

Quanto a reflexão sobre a prática, é comum que todos reflitamos na e sobre a ação que desenvolvemos, o que nem sempre nos torna um profissional reflexivo. Há uma distinção entre uma postura reflexiva do profissional e a reflexão esporádica. Nesse sentido, Perrenoud (2002) aponta que para o desenvolvimento de uma autêntica prática reflexiva essa postura deve se tornar constante num imbricamento constante da ação e reflexão, independentemente dos obstáculos e frustrações que delas possam decorrer.

No tocante a contribuição para a formação continuada, sabemos que esta ultrapassa os limites formais de ensino assumindo um caráter contínuo. Quanto as motivações para a formação continuada, Flores e seus colaboradores (2009, p. 132) consideram quatro questões fundamentais que levariam dos docentes a buscarem tal formação:

Nesta dimensão distinguimos quatro tipos de motivações: i) motivações políticas (relacionadas com a implementação de políticas educativas nacionais e/ou locais), ii) pedagógicas (associadas à expansão de perspectivas ligadas a uma maior eficácia no ensino), iii) práticas (resolução de questões ou exigências relacionadas com o próprio ensino) e emancipatórias (associadas ao seu próprio desenvolvimento).

De forma mais global, podemos pensar que a busca por essa formação se centra em dois aspectos motivacionais: os extrínsecos e os intrínsecos. Os extrínsecos estão voltados aos anseios sociais, políticas educacionais e necessidade de formação que atenda aos novos reptos 
e constantes mudanças do sistema educativo. Podemos perceber isso na alocução da formanda aqui denominada de Professora 4.

É notório que as instituições exigem cada vez mais profissionais competentes e qualificados para execução de um trabalho eficiente e eficaz no campo de atuação. Sendo assim, é fundamental uma formação compatível aos tempos modernos, os quais apresentam desafios diversos, o que requer mudanças na educação e profissionais revitalizados. (PORTFÓLIO 4, 2012).

Já quanto aos aspectos de ordem intrínsecos, são aqueles mais voltados para o crescimento pessoal e profissional do docente. Há uma motivação de ordem íntima como podemos perceber evidências ao observarmos o pensamento de uma das docentes-estudante. "Vale lembrar que é preciso querer aprender para que o processo seja concretizado". (PORTFÓLIO 5, 2012).

Em suma, não significa que a qualidade do ensino seja responsabilidade apenas do docente, mas em sendo o ensino uma atividade complexa, requer dos que a desempenham um processo contínuo de formação.

\section{CONSIDERAÇÕES DO PROCESSO INVESTIGATIVO}

Das análises preliminares a partir dos portfólios escritos pelos formandos, destacamos a motivação de ordem extrínseca e intrínseca que levaram esses docentes-estudantes a buscarem uma formação continuada, elegendo o curso de Segunda Licenciatura em Ciência da Natureza e Matemática, por ser objeto de atuação de todos os cursistas. Salientamos que na busca por essa formação havia uma necessidade aparente pela aquisição de novos conteúdos, fossem eles de ordem conceituais ou metodológicos mesmo já atuando nas disciplinas que lecionavam há algum tempo. As experiências que os mesmos possuíam, eram timidamente relatadas o que, de certa maneira, fez com que não se constatasse tão explicitamente o processo de uma prática reflexiva desses docentes.

Portanto, é imperioso que na construção, organização e desenvolvimento de um projeto dessa natureza, a instituição que se proponha a desenvolvê-lo considere o público a que se destina, considerando suas necessidades, expectativas, e especialmente, experiências para que, de fato, possam contribuir para uma prática reflexiva e ressignificação da mesma. 


\section{REFERÊNCIAS}

FLORES, M. A.; et al. IN: FLORES, Maria Assunção; SIMÃO, Ana Maria Veiga (org.) Aprendizagem e desenvolvimento profissional de professores: contextos e perspectivas. Portugal: Edições Ramada, 2009.

GATTI, B. A.; BARRETO, E. S. de S. B. Professores do Brasil: impasse e desafios. Brasília: UNESCO, 2009.

HERNÁNDEZ, F. Transgressão e Mudança na Educação: os projetos de trabalho. Porto Alegre: Artmed, 1998.

MORGADO, J. C. Currículo e profissionalidade docente. Porto: Porto Editora, 2005.

PERRENOUD, P. A prática reflexiva no ofício do professor: profissionalização e razão pedagógica. Trad. Cláudia Schiling. Porto Alegre: Artmed Editora, 2002.

PORTFÓLIO 1. 2012. 15 f. Trabalho elaborado para finalização do $1^{\circ}$ semestre letivo do Curso de Ciências da Natureza e Matemática do IFRN.

PORTFÓLIO 2. 2012. 11 f. Trabalho elaborado para finalização do o $1^{\circ}$ semestre letivo do Curso de Ciências da Natureza e Matemática do IFRN.

PORTFÓLIO 3. 2012. 35 f. Trabalho elaborado para finalização do $1^{\circ}$ semestre letivo do Curso de Ciências da Natureza e Matemática do IFRN.

PORTFÓLIO 4. 2012. 32 f. Trabalho elaborado para finalização do $1^{\circ}$ semestre letivo do Curso de Ciências da Natureza e Matemática do IFRN.

PORTFÓLIO 5. 2012. 09 f. Trabalho elaborado para finalização do $1^{\circ}$ semestre letivo do Curso de Ciências da Natureza e Matemática do IFRN.

TARDIF, M. Saberes docentes e formação profissional. Petrópolis, RJ: Vozes, 2002.

YIN, R. Estudo de Caso: planejamento e Métodos. Porto Alegre: Bookman, 2005.

VEIGA SIMÃO, A. M. O "Portfolio" como instrumento na auto-regulação da aprendizagem uma experiência no ensino superior pós-graduado. In SÁ-CHAVES, Idalina (Coord.). Os "Portfolios" Reflexivos (Também) Trazem Gente Dentro: reflexões em torno do seu uso na humanização dos processos educativos. Porto: Porto Editora, 2005. 